\title{
FTIR, UV-Vis, Magnetic, Mass Spectral and XRD studies of Ni (II) complex with Pioglitazone: An Oral Antidiabetic Drug
}

\author{
OM PRAKASH CHOUHAN and GEORGE JACOB \\ Department of Chemistry, Saifia Science College, Barkatullah University, Bhopal - 462001, India \\ Department of Science, Blyth Academy, Lawrence Park, Ontario (Canada) \\ ${ }^{*}$ Corresponding author E-mail: omprakashchouhan84@gmail.com \\ http://dx.doi.org/10.13005/ojc/300407
}

(Received: October 30, 2014; Accepted: December 01, 2014)

\begin{abstract}
Metal complex of pioglitazone hydrochloride (PLZ) drug with $\mathrm{Ni}(\mathrm{II})$ ion is synthesized and characterized using analytical data, molar conductance, IR, UV-Vis, magnetic, mass spectral and $\mathrm{XRD}$ studies. From the analytical data, the complex is proposed to have general formula $\left[\left(\mathrm{C}_{19} \mathrm{H}_{19} \mathrm{~N}_{2} \mathrm{O}_{3} \mathrm{~S}\right)^{+}{ }_{2} \mathrm{Ni}\right] 2 \mathrm{Cl}$. The conductometric titration using monovariation method reveals that complex is $L_{2} M$ type. The molar conductance data indicates that the metal chelate is ionic. IR spectra show that PLZ is coordinated to the metal ions in which ligand molecules lie horizontally joining the central $\mathrm{Ni}^{(I)}$ atoms. The electronic spectra and magnetic moment reveal that the chelate have tetrahedral geometry. Mass spectra is also used to confirm the proposed formula and the possible fragments resulted from fragmentation of PLZ and its $\mathrm{Ni}{ }^{(I)}$ complex. XRD data also used to calculate the various parameters like particle size, porosity, volume of unit cell and density.
\end{abstract}

Key words: Pioglitazone, Metal complex, IR, UV-Vis, magnetic, mass, XRD.

\section{INTRODUCTION}

Pioglitazone hydrochloride is an oral antidiabetic agent that has been shown to affect abnormal glucose and lipid metabolism associated with insulin resistance by enhancing insulin action on peripheral tissues in animals. It is used in the treatment of type-II diabetes also known as non insulin dependent diabetes mellitus ${ }^{1}$ (NIDDM) or adult onset diabetes. Currently, it is marketed under the trade name Actos It belongs to a class of compounds known as the "thiazolidinediones". Pioglitazone hydrochloride $\left(\mathrm{C}_{19} \mathrm{H}_{20} \mathrm{~N}_{2} \mathrm{O}_{3} \mathrm{~S} \cdot \mathrm{HCl}\right)$ exists as an odorless white crystalline powder. It has structural formula as shown in Fig.1, with a molecular weight 392.90 daltons. It has low solubility and high permeability. It is insoluble in water and ether, little soluble in acetonitrile and acetone, and completely soluble in dimethylformamide (DMF). For oral administration it is available in the form of tablets in market. It exhibits slow gastrointestinal absorption rate and inter individual variation of its bioavailability ${ }^{2}$. A survey of literature reveals that metal complexes of many drugs have been found to be more effective than the drug alone ${ }^{3}$ therefore, much attention is given to the use of thiazolidinedione hydrochloride due to their high complexing nature with essential 
metals. In view of the above and in continution of our work, it is interesting to have an insight into the synthesis of nickle complex with pioglitazone and to diagnose various structural aspects of the isolated complex. Here the synthesis and characterization of nickle chloride with pioglitazone hydrochloride has been described.

\section{EXPERIMENTAL}

\section{Ligand- Metal ratio}

(a). To find out the ligand metal ratio, initially conductometric titration using monovariation method are carried out at $27 \pm 1 \stackrel{\circ}{ } \mathrm{C}$ and 0.005 $\mathrm{M}$ solution of pioglitazone hydrochloride is prepared in DMF. Similarly, solution of nickle chloride $\left(\mathrm{NiCl}_{2}\right)$ is prepared in the ethanol of $0.01 \mathrm{M}$ concentration. $10 \mathrm{ml}$ of ligand is diluted to $100 \mathrm{ml}$ with the same solvent. The ligand is titrated conductometrically against metal salt solution taken in burette using fraction of $1 \mathrm{ml}$. Conductance is recorded after each addition with proper stirring. Results is plotted in the form of graph between corrected conductance and volume of metal salt added. From the equivalence point in the graph, ratio between ligand and metal are noted to be 2:1 $\left(\mathrm{L}_{2} M\right)$.

(b). Formation of the complex in $2: 1\left(L_{2}: M\right)$ ratio isalso confirmed by Job's method ${ }^{4}$ of continuous variation as modified by Turner and Anderson $^{5}$ Fig. 2(a)-(b) using conductance as index property, from these values the stability constant ( $\log k$ ) and free energy change (DF), were also calculated ${ }^{6-11}$.

\section{MATERIAL AND METHOD}

All chemicals are used of analytical grade (A. R.). They include pure pioglitazone hydrochloride with molecular formula $\left(\mathrm{C}_{19} \mathrm{H}_{20} \mathrm{~N}_{2} \mathrm{O}_{3} \mathrm{~S}\right.$. $\left.\mathrm{HCl}\right)$, received from Morepen Laboratories, Distt. Solan (H.P.) India. The metal salt of $\mathrm{NiCl}_{2}$ obtained from $\mathrm{Hi}$ media Laboratory, Mumbai, India. Ethanol and DMF were used as a solvent.

\section{Synthesis of Complex}

A weighed quantity of "Pioglitazone" (2 mole) is dissolved separately in minimum quantity of DMF. The $\mathrm{NiCl}_{2}$ solution is prepared by dissolving separately in the ethanol. Ligand solution is added slowly with stirring into the solution of metallic salt at room temperature; maintain the $\mathrm{pH}$ between 6.0 to 6.5 by adding dilute $\mathrm{NaOH}$ solution. On refluxing the mixture for 3-4 $\mathrm{h}$ and on cooling, the precipitates of metal complex is obtained, which are filtered off, washed well with DMF and ethanol finally dried in vacuum and weighed.

\section{Instrumentation}

Molar conductances of complexes are measured by using Systronics Digital Conductivity meter. The elemental analysis of the isolated complex is carried out by using Coleman Analyzer Model at the Departmental Micro Analytical Laboratory, CDRI, Lucknow, India. IR spectra of ligand and complex are recorded with Perkin Elmer Model 577 Spectrophotometer in the range of $4000-450 \mathrm{~cm}^{-1}$ as $\mathrm{KBr}$ pellets $\mathrm{CDRI}$, Lucknow, India. The UV-Vis spectra of the ligand and complex are recorded with Perkin Elmer UV Winlab in the range of 200-800 nm Punjab University, Chandigarh, India. The ESI-MS Mass Spectra of pioglitazone and its nickle complex are performed on Waters UPLC-TQD Mass Spectrometer at CDRI, Lucknow, India which provides information about the complex by examining the fragmentation pattern and total mass of the complex. $X$-ray diffraction studies are carried out by $X$-ray Diffractometer model with $45 \mathrm{kV}$ rotating anode and $\mathrm{Cuk}_{ \pm}\left(1 \mathrm{~W}=1.54060 \mathrm{~A}^{\circ}\right)$ radiation at Punjab University, Chandigarh, India. The samples are scanned in the range $10.000^{\circ}$ to 79 . $9784^{\circ}\left(2_{s}\right)$ powder data were indexes using computer software (FPSUIT V2.0).

\section{RESULTSAND DISCUSSION}

The formation of metal complex with organic compounds has long been recognized. The synthesized complex is coloured and stable, being soluble in DMSO and insoluble in water, ethanol etc. Analytical data and conductometric studies suggest 2:1 $\left(L_{2}: M\right)$ ratio. Structures for the complex is shown in Fig. 3.

\section{Composition of metal complex}

The isolated solid complex of Ni metal ions with the PLZ ligand is subjected to elemental analyses (C, H, N, S and metal content) and molar conductance. The results of physical and analytical data are given in Table 1. 
<smiles>CCc1ccc(CCOc2ccc(CC3SC(=O)NC3=O)cc2)nc1</smiles>

Fig. 1: Structure of pioglitazone hydrochloride

\section{PIOGLITAZONE WITH $\mathbf{N i C l}_{2}$ (Modified Job's method)}
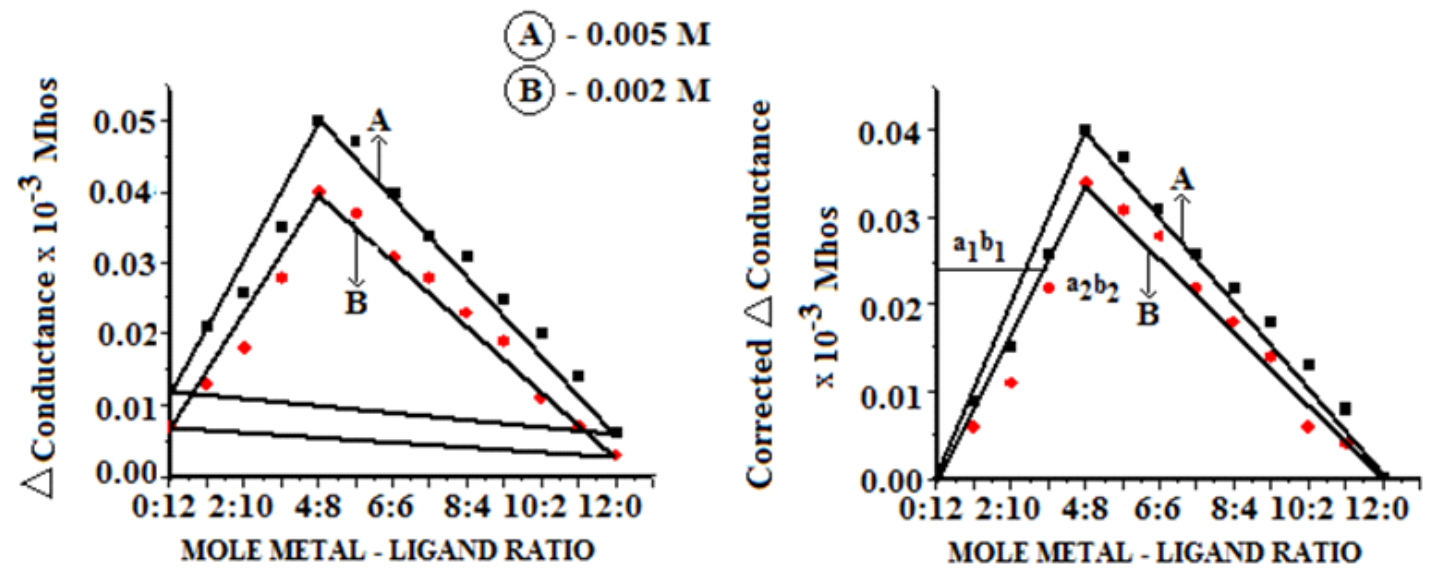

Fig. 2(a) Job's curve (b) Modified Job's curve

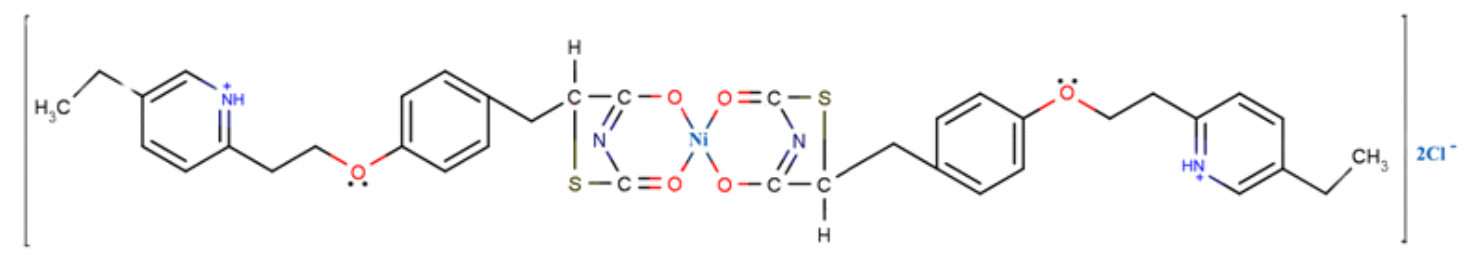

Fig. 3: Structure of PLZ-Ni complex

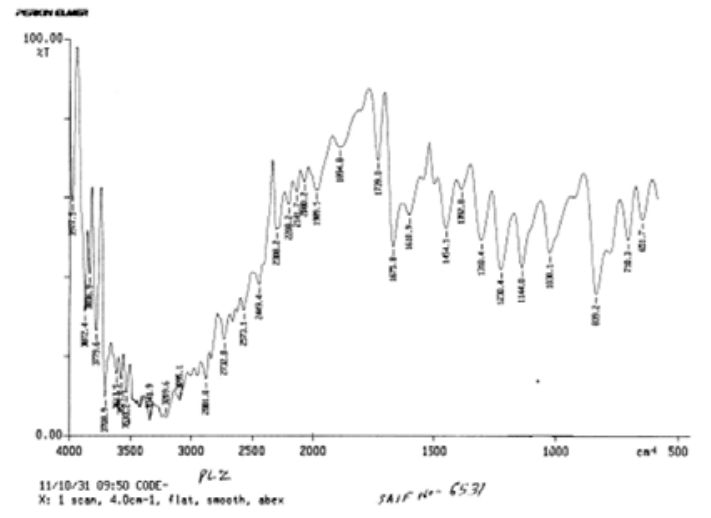

Fig. 4(a): IR spectra of pioglitazone (PLZ) drug

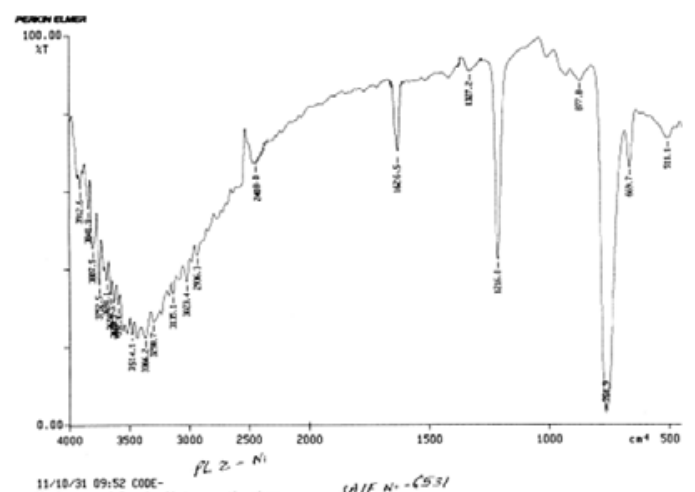

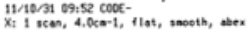

Fig. 4(b): IR spectra of PLZ -Ni Complex 


\section{Infra-red Spectral Studies}

The IR spectra of ligand and isolated complex are recorded within the range 4000-400

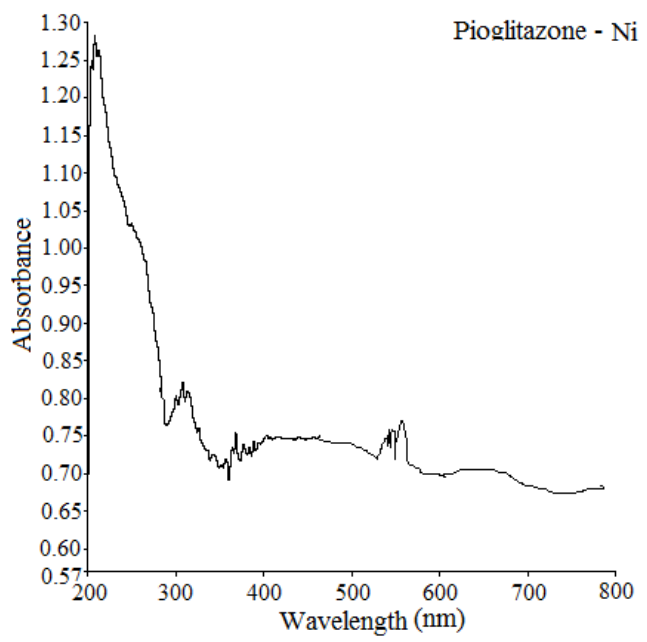

Fig.5: Electronic spectra of PLZ-Ni complex

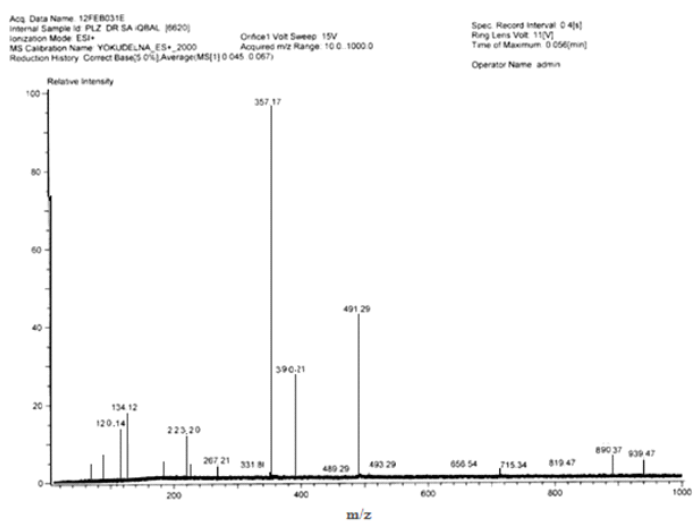

Fig. 6 (a): Mass spectra of PLZ drug $\mathrm{cm}^{-1}$. In order to determine the coordination sites that may be involved in chelation, we compared the IR spectra of the PLZ with their Ni complex as shown in Fig. $4(a, b)$.

The stretching vibration band in ligand at $3613 \mathrm{~cm}^{-1}$ can be ascribed to $\mathrm{N}-\mathrm{H}$ group but in the complex this group is found at $3656 \mathrm{~cm}^{-1}$. The $\mathrm{C}=\mathrm{O}$ stretching frequency of the ligand appear at $1675 \mathrm{~cm}$ ${ }^{1}$ while in nickle complex, it is shifted at $1626 \mathrm{~cm}^{-1}$. The shift of $\mathrm{C}=\mathrm{O}$ group by changing frequency in the complex indicate that these are involved in the complexation. New bands are found in the spectra of complexes in the region $507 \mathrm{~cm}^{-1}$ which is assigned to $\mathrm{M}-\mathrm{O}$ stretching vibrations. The proposed structure for the isolated complex is also supported by IR absorptions ${ }^{12-18}$.

\section{UV-Visble and magnetic moment studies}

The electronic spectra of Ni complex Fig.5 show three bands at $10845 \mathrm{~cm}^{-1}, 15076 \mathrm{~cm}^{-1}$ and

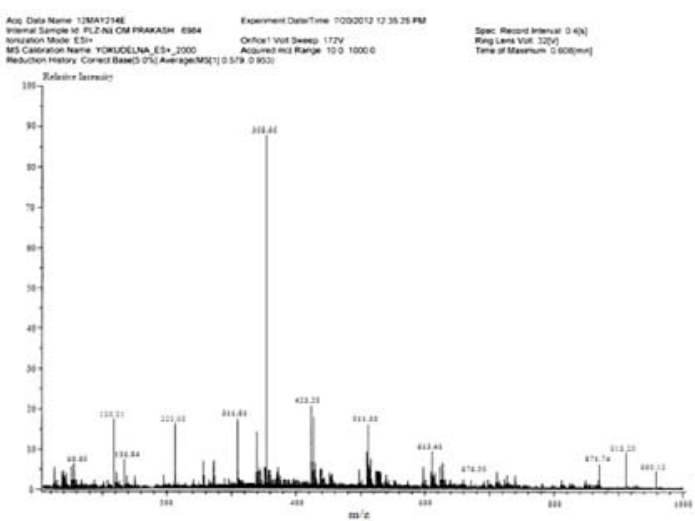

Fig. 6 (b): Mass spectra of PLZ - Ni complex

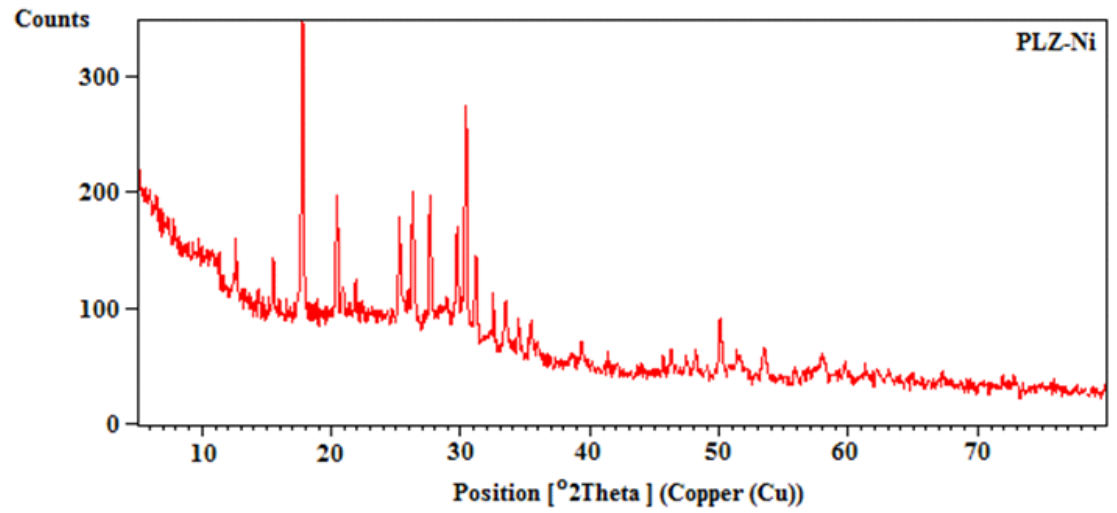

Fig. 7: X-ray diffraction pattern of PLZ -Ni complex 
$10768 \mathrm{~cm}^{-1}$ are assigned to ${ }^{3} \mathrm{~A}_{2 g}(\mathrm{~F}) \rightarrow{ }^{3} \mathrm{~T}_{2 \mathrm{~g}}(\mathrm{~F}),{ }^{3} \mathrm{~A}_{2 \mathrm{~g}}(\mathrm{~F})$ ${ }^{3} \mathrm{~T}_{19}(\mathrm{~F})$ and ${ }^{3} \mathrm{~A}_{2 g}(\mathrm{~F}) \rightarrow{ }^{3} \mathrm{~T}_{19}(\mathrm{P})$ transitions respectively indicated for tetrahedral geometry around $\mathrm{Ni}$ (II) complex ${ }^{19-20}$. The magnetic moment value of $\mathrm{Ni}(\mathrm{II})$ complex is 3.36 B.M suggests the presence of two unpaired electrons, which reveals the spin free nature of the complex corresponding a tetrahedral stereochemistry.

\section{Mass Spectral studies}

Mass spectra represent the intensities of signals at various $\mathrm{m} / \mathrm{z}$ values. It is highly characteristic of the compound that no two compounds can have similar mass spectra. It provides information regarding the molecular structure of organic and inorganic compounds. Mass spectrum of PLZ and its Ni complex are presented in Fig.6 (a)-(b).

Assignment of $\mathrm{Ni}$ complex, molecular formula i.e. $\left[\left(\mathrm{C}_{19} \mathrm{H}_{19} \mathrm{~N}_{2} \mathrm{O}_{3} \mathrm{~S}\right)^{+}{ }_{2} \mathrm{Ni}\right] 2 \mathrm{Cl}$, (Mol.Wt. $=$ 915.39), $\mathrm{m} / \mathrm{z} 918$ due to $\left[\left(\mathrm{C}_{19} \mathrm{H}_{19} \mathrm{~N}_{2} \mathrm{O}_{3} \mathrm{~S}\right)^{+}{ }_{2} \mathrm{Ni}\right] 2 \mathrm{Cl}$ or $\left(\mathrm{ML}_{2}{ }^{\prime \prime}\right)^{+}$Molecular ion peak $\left(\mathrm{m}^{+}\right) ; \mathrm{m} / \mathrm{z} 358$ due to $\left.\left[\mathrm{C}_{19} \mathrm{H}_{20} \mathrm{~N}_{2} \mathrm{O}_{3} \mathrm{~S}\right)\right]^{+}$. base peak ion $100 \%$ relative abundance, $\mathrm{m} / \mathrm{z} 223$ due to $\left[\mathrm{C}_{10} \mathrm{H}_{9} \mathrm{NO}_{3} \mathrm{~S}\right]^{+} \cdot \mathrm{m} / \mathrm{z} 136$ due to $\left[\mathrm{C}_{9} \mathrm{H}_{12} \mathrm{~N}\right]^{+}, \mathrm{m} / \mathrm{z} 120$ due to $\left[\mathrm{C}_{8} \mathrm{H}_{10} \mathrm{~N}\right]^{+}$. radical ion respectively.

\section{X-Ray diffraction studies}

The crystallographic data (scattering angles, d-spacing, and relative intensities) for PLZ - Ni complex is calculated by using computer software (FPSUIT 2.0V). The X-ray diffraction pattern for Ni complex is shown in Fig. 7. It can be seen from the figure that the main characteristic scattering peaks for PLZ-Ni are at $18^{\circ}, 20^{\circ}, 28^{\circ}$ and $30^{\circ}$ positions.

From the crystallographic data ${ }^{21-26}$ unit cell parameters are obtained for $\mathrm{Ni}$ complex which attributed to orthorhombic crystal system. The particle size of pioglitazone-nickle complex is 19.871 microns respectively, which is calculated from X-ray line broadening using the Scherrer formula; $t=\frac{\kappa \lambda}{\beta \cos \theta}$ where $t$ is the thickness of the sample, $\kappa$ is a coefficient and is equal to 0.89 here, $\beta$ is the half-maximum line width, and $\lambda$ is the wavelength of $\mathrm{X}$-rays. The porosity is $0.211 \%$ 
calculated by formula; $\frac{d_{t r u e}-d_{o b s} \times 100}{d_{t r u}}$ and volume of the unit cell is $14059.63 \mathrm{~A}^{\circ}$ which is calculated by Volume $(\AA)=$ abc where $a, b$ and $c$ are lattice parameters. Density $=$ Weight/Volume is found $0.0595 \mathrm{~g} / \mathrm{cm}^{3}$ respectively.

\section{CONCLUSION}

In the present paper, we have synthesized the complex of pioglitazone drug with $\mathrm{Ni}^{(I I)}$ metal. The structure of the complex is confirmed by the spectroscopic techniques and XRD study. Analytical data agrees with the molecular formula of the complex. Molar conductance value supports the ionic nature of the complex. The tentative structure assigned to the complex on the basis of analytical data were further supported by modren spectroscopic methods like IR, Mass spectral studies. In mass spectra of nickle complex the base peak of the ligand appear on $\mathrm{m} / \mathrm{z} 358$ while short peak for Ni complex appear on $\mathrm{m} / \mathrm{z} 915$ which is quite supportive. A detailed study of X-ray also supports the complex formation and various parameters such as particle size, porosity, volume of unit cell and density of synthesized complex is evaluated.

\section{REFERENCES}

1. Abbasi, F.; Lima, N. K.; Reaven, G. M. Metabolism. 2009, 58, 373378.

2. Kouichi, Diab. Res. Clin. Pract. 2005, 68, 250-257.

3. Sharma, S.; Iqbal, S. A.; Bhattacharya, M. Orient. J. Chem. 2009, 25(4), 1101-1104.

4. Job, P. Annales de Chimie. 1928, 10, 113.

5. Turner, S. E.; Anderson R. C. J. Am.Chem. Soc. 1949, 71(3), 912-914.

6. Irving, H.; Rossotti, H.S. J. Chem. Soc.1955,1176.

7. Irving, H.; Rossotti, H.S. J. Chem. Soc.1954, 3397.

8. Irving, H.; Rossotti, H.S. J. Chem. Soc.1953, 2904.

9. Prakash, Om.; Krishan, B.; Jacob, G. Orient. J. Chem. 2013, 29(2), 823-828.

10. Prakash, Om.; Iqbal, S. A.; Jacob, G. Orient. J. Chem. 2013, 29(3), 1079-1084.

11. Iqbal, S. A .; Zaafarny, I. Orient. J. Chem. 2012, 28, 613-618.

12. Weissberger, A. Inter Science Publ. New York. XI, (1956).

13. Nakamotto, K. John Willey and son's. New York.(1963).

14. Rao, C. N. R. Academic press, New York. (1963).
15. Dyer, J. R. Prentice Hall of India Pvt. Ltd. (1966).

16. Tawkir, M.; Khairou, K.; Zaafarany, I. Orient. J. Chem. 2012, 28(4), 1697-1710

17. Krishan, B.; Tawkir, M.; Iqbal, S. A. Orient. J. Chem. 2012, 28(4), 1883-1888.

18. Chauhan, G. R.; Kharadi, G. J.; Patel, K. D. Orient. J. Chem. 2010, 26(4), 1431-1436.

19. Van Vleck, J. H.; Frank, A. Physical Review. 1929, 34(1), 1494-1496.

20. Rastogi, G.; Rastogi,R. K.; Ahmad S. Orient. J. Chem. 2008, 24(3),1077-1080

21. Krishan, B.; Prakash, O.; El-Mossalamy, E. H. Orient. J. Chem. 2013, 29(1), 381-388.

22. Krishan, B.; Tawkir, M.; Iqbal, S. A. Orient. J. Chem. 2012, 28(4), 1883-1888.

23. Tawkir, M.; Krishan, B.; Iqbal, S. A.; Zaafarany, I. Material Science Research india. 2010, 9(1), 93-98.

24. Bragg, W. L.; Bragg, W. H. The crystalline state -A general survey, London, (1993).

25. Jenkins, R.; Devries, J. L. Worked examples in X-ray analysis, New York, Springer Verlog (1970).

26. Chouhan, O. P.; Chouhan, H. Material Science Research india. 2014, 11(1), 75-81. 